\title{
Biology and pathogenesis of Acanthamoeba
}

\author{
Ruqaiyyah Siddiqui ${ }^{1}$ and Naveed Ahmed $\operatorname{Khan}^{1,2^{*}}$
}

\begin{abstract}
Acanthamoeba is a free-living protist pathogen, capable of causing a blinding keratitis and fatal granulomatous encephalitis. The factors that contribute to Acanthamoeba infections include parasite biology, genetic diversity, environmental spread and host susceptibility, and are highlighted together with potential therapeutic and preventative measures. The use of Acanthamoeba in the study of cellular differentiation mechanisms, motility and phagocytosis, bacterial pathogenesis and evolutionary processes makes it an attractive model organism. There is a significant emphasis on Acanthamoeba as a Trojan horse of other microbes including viral, bacterial, protists and yeast pathogens.
\end{abstract}

\section{Background}

Acanthamoeba is an opportunistic protist that is ubiquitously distributed in the environment. Acanthamoeba has two stages in its life cycle, an active trophozoite stage that exhibits vegetative growth and a dormant cyst stage with minimal metabolic activity. It is a causative agent of cutaneous lesions and sinus infections, visionthreatening keratitis and a rare but fatal encephalitis, known as granulomatous amoebic encephalitis [1-3]. The ability of Acanthamoeba to (i) produce serious human infections associated with a rise in the number of immunocompromised patients and contact lens wearers, (ii) their potential role in ecosystems, (iii) ability to act as a host/reservoir for microbial pathogens, and (iv) model organism for motility studies has led to a significant interest in this organism over the years (Figure 1). Furthermore, Acanthamoeba may have veterinary significance as demonstrated by the presence of amoebae in diseased or dead cows, dogs, pigs, rabbits, pigeons, sheep, reptiles, fish, turkeys, keel-billed toucan, Ramphastos sulfuratus, horses [4-6].

\section{Discovery of Amoebae}

Amoebae are among the earliest eukaryotes that have been studied since the discovery of the early microscope, e.g., Amoeba proteus, or closely related Chaos that is a genus of giant amoebae, varying from $1-5 \mathrm{~mm}$ in length. Based on rRNA sequences, it is estimated that amoebae have diverged from the main line of eukaryotic descent,

\footnotetext{
* Correspondence: Naveed5438@gmail.com

${ }^{1}$ The Aga Khan University, Karachi, Pakistan

Full list of author information is available at the end of the article
}

sometimes between the divergence of yeast $\left(\sim 1.2 \times 10^{9}\right.$ years ago) and the divergence of plants and animals $(\sim 1$ $\times 10^{9}$ years ago). Over the past several decades, these organisms have gained increasing attention due to their diverse roles in the ecosystem and in particular, their role in causing serious and sometimes fatal human infections (Figure 2).

- Entamoeba histolytica is a parasitic protist that was discovered in 1873 from a patient suffering from bloody dysentery $[7,8]$ and named E. histolytica in $1903[9,10]$. This species was separated into one pathogenic (E. histolytica) and another non-pathogenic (E. dispar) [11], which also is capable of producing experimental lesions [12] and questioned by some authors if really it is unable to cause human disease [13].

- Naegleria is a free-living amoebae that was first discovered by Schardinger in 1899, who named it "Amoeba gruberi". In 1912, Alexeieff suggested its genus name as Naegleria, and much later in the 1970, Carter identified Naegleria fowleri as the causative agent of fatal human infections involving the central nervous system (CNS) [14].

- Sappinia diploidea is a free-living amoeba that was isolated from the faeces of lizards and from the soil in 1908-09, and then described as a causative agent of granulomatous amoebic encephalitis in 2001 [15]. - Balamuthia mandrillaris was discovered in 1986, from the brain of a baboon that died of meningoencephalitis and was described as a new genus, i.e., Balamuthia $[3,16]$. So far, only one species has been 


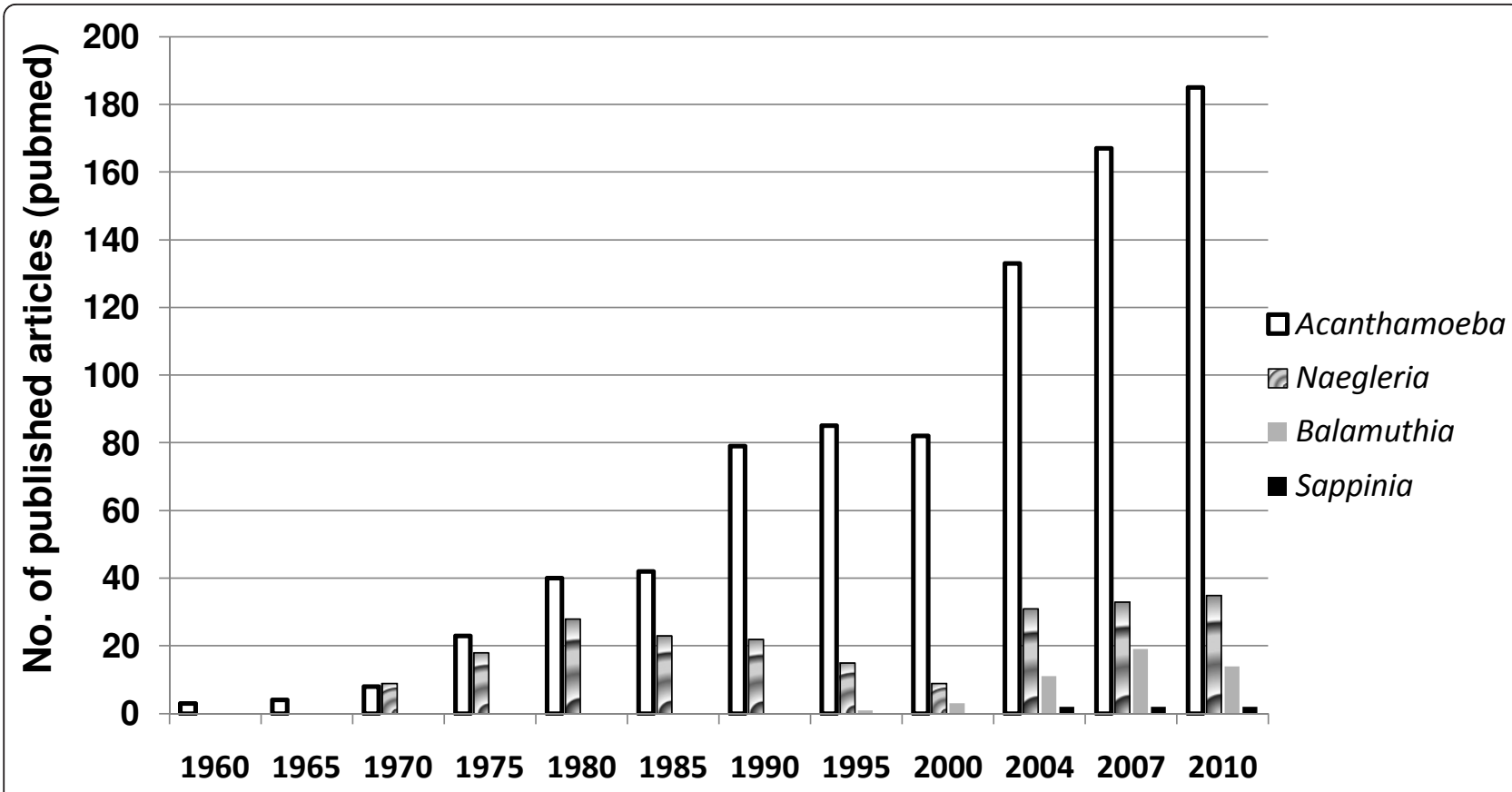

\section{Year of Publication}

Figure 1 Increasing scientific interest in the field of free-living amoebae as determined by published articles over the last five decades. A pubmed search using "Acanthamoeba", "Balamuthia", Naegleria" or "Sappinia" was carried out.

identified, B. mandrillaris. The majority of isolates have been isolated from necropsies while organicrich soil has been suggested as a potential source. Like Acanthamoeba, it is known to produce infections of the central nervous system, lungs, sinuses and skin. Worryingly, granulomatous encephalitis due to $B$. mandrillaris has been reported in immunocompetent individuals indicating its potential threat to human and animal health.

- In 1930, Acanthamoeba was discovered as a contaminant of yeast culture, Cryptococcus pararoseus and was later placed in the genus Acanthamoeba, and then described as a causative agent of Acanthamoeba granulomatous encephalitis (AGE) in the 1960s and of keratitis in 1970s [17].

\section{Biology of Acanthamoeba}

The term acanth (Greek "acanth" means "spikes") was added to "amoeba" to indicate the presence of spine-like structures (now known as acanthopodia) on its surface. It contains one or more prominent contractile vacuoles, whose function is to expel water for osmotic regulation [18]. Other types of vacuoles in the cytoplasm include lysosomes, digestive vacuoles and a large number of glycogen-containing vacuoles. The plasma membrane consists of proteins (33\%), phospholipids (25\%), sterols
(13\%), and lipophosphonoglycan (29\%) [19,20]. The major phospholipids in Acanthamoeba are phosphatidylcholine (45\%), phosphatidylethanolamine (33\%), phosphatidylserine (10\%), phosphoinositide (6\%), and diphosphatidylglycerol (4\%). The main fatty acids chains in Acanthamoeba are oleic acids (40-50\%), and longer polyunsaturated fatty acids (20-30\%) [21]. Acanthamoeba contains low levels of glycolipids. Glucose accounts for about $60 \%$ of the sugars of the glycolipids of the whole cells and of the plasma membranes. Among sterols, the non-saponifiable fraction of the total lipids extracted from the trophozoites of pathogenic Acanthamoeba possesses ergosterol and 7-dehydrostigmasterol [20]. Acanthamoeba has been shown to produce prostaglandins [22].

Acanthamoeba trophozoite possesses large numbers of mitochondria (Figure 3). The genome size of mitochondrial DNA from A. castellanii belonging to T4 genotype is 41,591 bp [23]. Acanthamoeba normally possesses a single nucleus that is approximately one sixth the size of trophozoite (Figure 3), but multinucleate amoebae have been observed. The genome size of A. castellanii Neff strain, belonging to T4 genotype is approximately 45 Mb http://www.hgsc.bcm.tmc.edu/microbial-detail.xsp? project_id $=163$. Based on the coding sequence (CDS features, exon) analysis of 200 genes, it was calculated that there are on average 3 exons per gene (for comparison, 


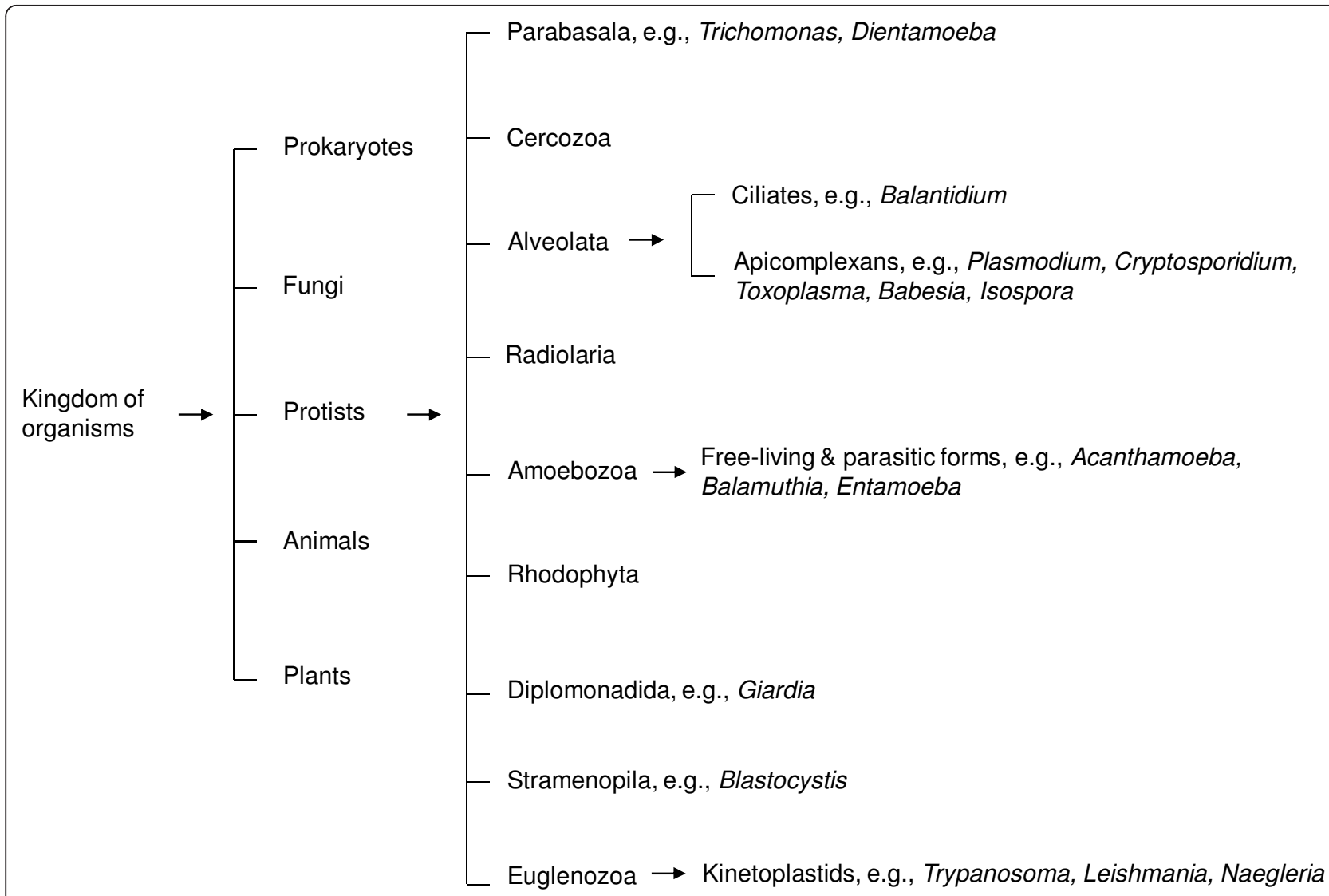

Figure 2 The classification of protists, based on ribosomal rRNA sequences (modified from Khan NA Acanthamoeba: Biology and Pathogenesis, Caister Academic Press, 2009, ISBN: 978-1-904455-43-1).

E. histolytica possess 1.3 exons per gene, and Dictyostelium discoideum possess 2.3 exons per gene) [24].

Acanthamoeba has long been studied as a model eukaryotic cell with special emphasis on the actin cytoskeleton-based motility [25]. Acanthamoeba moves relatively fast compared to other cells, with a locomotory rate of approximately $0.8 \mu \mathrm{m} /$ second. The movement involves the formation of a hyaline pseudopodium. The manner of Acanthamoeba movement is similar both at solid substrata and water-air interface. Adhesion forces developed between Acanthamoeba and the water-air interface are greater than gravity, and thus amoebae are also transported passively without detachment from the water surface [26]. Actin microfilaments are most concentrated just beneath the plasma membrane, and are responsible for resisting tension and forming cytoplasmic protrusions.

\section{Life cycle of Acanthamoeba}

Acanthamoeba has two stages in its life cycle, a vegetative trophozoite stage with a diameter of 13-23 $\mu \mathrm{m}$ and dormant cyst stage of $13-23 \mu \mathrm{m}$ (Figure 4 ). During the trophozoite stage (Greek "tropho" means "to nourish"), Acanthamoeba feeds on organic particles as well as other microbes and divides mitotically under optimal conditions (food supply, neutral $\mathrm{pH}, \sim 30^{\circ} \mathrm{C}$ ) and 50 $80 \mathrm{mOsmol}$ [27]. Exposure to harsh conditions result in cellular differentiation into a double-walled cyst form [28]. The outer walls consists of proteins and polysaccharides, while the inner wall possesses cellulose [29-31]. Both walls are normally separated by a space, except at certain points where they form opercula in the centre of ostioles (exit points for excysting trophozoite). The cyst wall composition for $A$. castellanii belonging to T4 genotype has been shown to contain $33 \%$ protein, 4 - 6\% lipid, 35\% carbohydrates (mostly cellulose), $8 \%$ ash, and $20 \%$ unidentified materials [29-31]. Using gas chromatography combined with mass spectrometry, the carbohydrate composition of cyst walls revealed a high percentage of galactose and glucose and small amounts of mannose and xylose [32]. Linkage analysis revealed several types of glycosidic linkages including the 1,4linked glucosyl conformation indicative of cellulose (Table 1). 


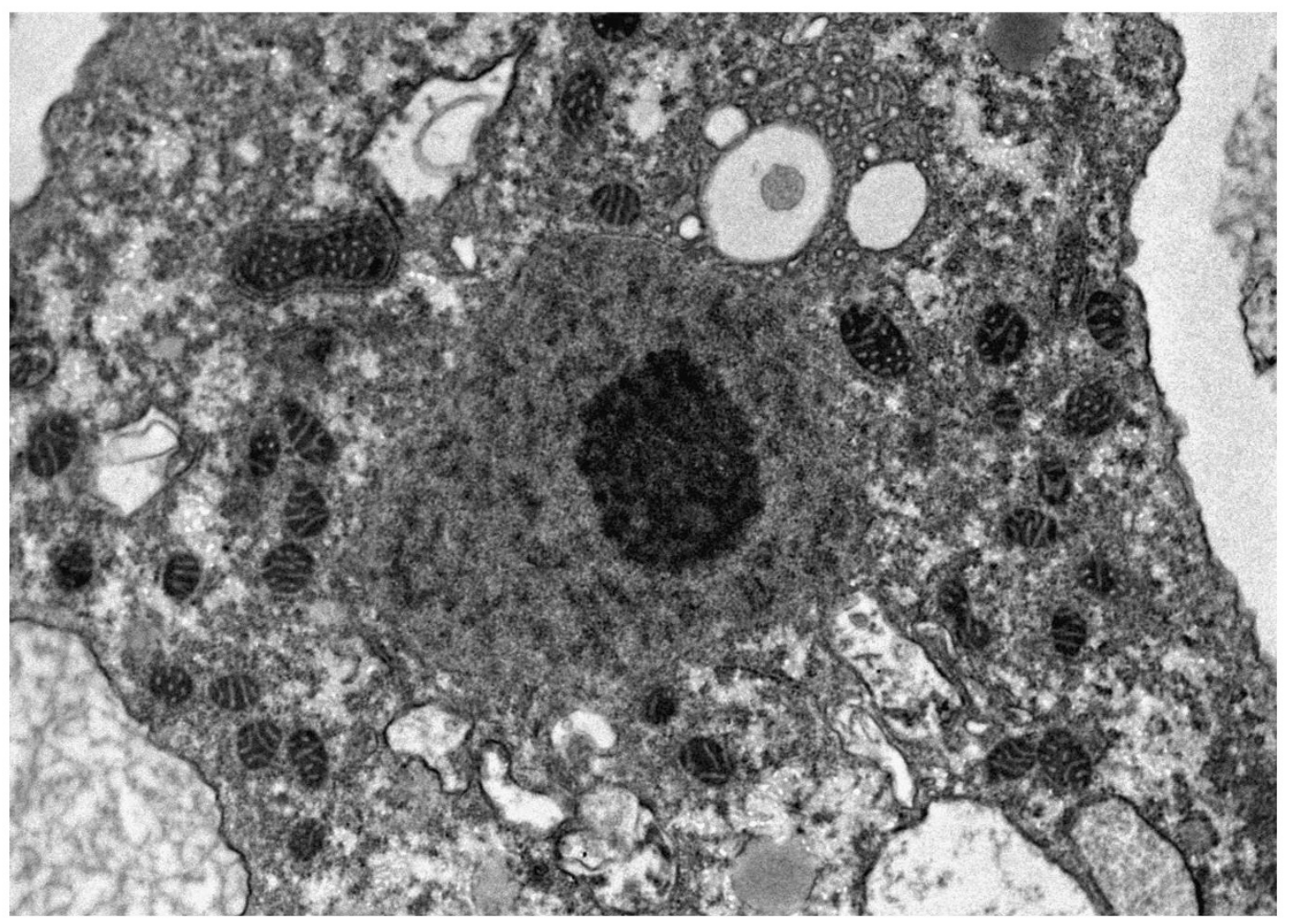

\section{$2 \mu \mathrm{m}$}

Figure 3 The transmission electron micrograph of Acanthamoeba trophozoite. $M$ is mitochondria; $N$ is nucleus; $V$ is vacuole and arrow indicates plasma membrane.

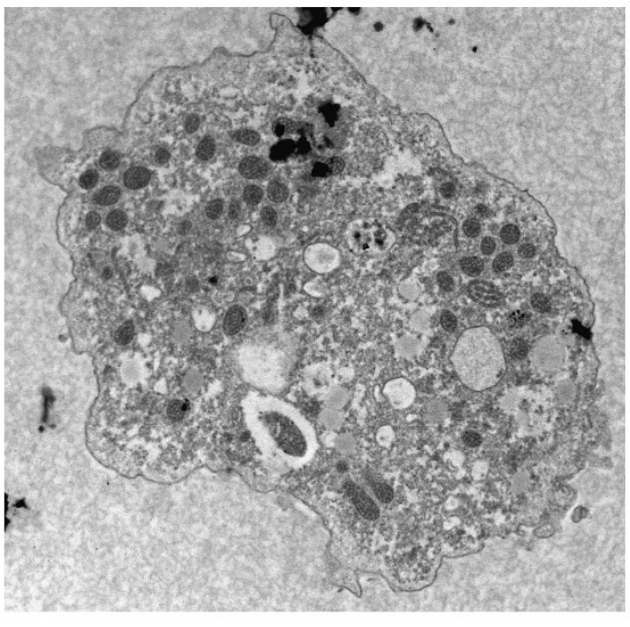

$2 \mu \mathrm{m}$

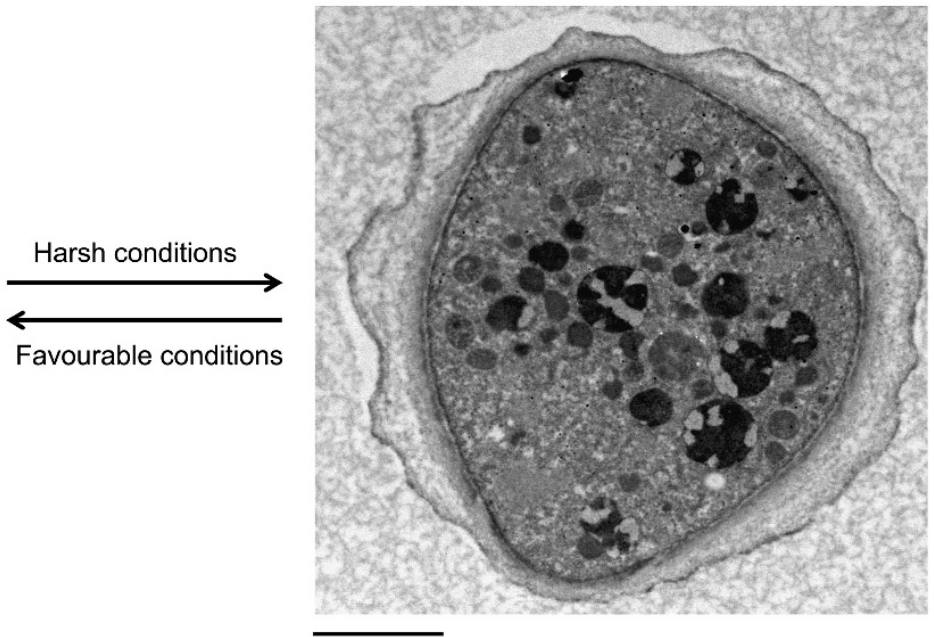

$2 \mu \mathrm{m}$

Figure 4 The life cycle of Acanthamoeba spp. Under favourable conditions, Acanthamoeba remains in the trophozoite form and divides mitotically (A) and produces infection, while under harsh conditions amoeba transforms into a dormant cyst form (B) that is highly resistant to harsh conditions. 
Table 1 Glycosyl linkage analysis of Acanthamoeba castellanii cyst wall saccharides (reproduced with permission from Dudley et al., 2009).

\begin{tabular}{lll}
\hline Glycosyl Residue $^{\mathbf{1}}$ & Area $^{\mathbf{2}}$ & Percentage Present \\
\hline Terminal Mannopyranose & 563313 & 3.2 \\
\hline 5 linked Xylofuranose/4XylP & 1236950 & 7.0 \\
\hline 3 linked Galactopyranose & 5038076 & 28.6 \\
\hline 4 linked Glucopyranose & 3908275 & 22.2 \\
\hline 3,4 linked Galactopyranose & 2392068 & 13.6 \\
\hline 3,4 linked Glucopyranose & 1063116 & 6.0 \\
\hline 2,4 linked Gluco or Galactopyranose & 783793 & 4.4 \\
\hline 4,6 linked Mannopyranose & 1368136 & 7.8 \\
\hline 3,6 Linked Galactopyranose & 1273911 & 7.2 \\
\hline
\end{tabular}

${ }^{1}$ Note that 5 linked xylofuranose and 4-linked xylopyranose are not distinguished in this assay as they have the same derivative. ${ }^{2}$ Area percentages are not corrected for response factor and thus may not be representative of molar ratios.

\section{Distribution in the environment and clinical settings}

Acanthamoeba has been isolated from diverse natural environments including sea water, ocean sediments, beaches, pond water, soil, fresh water lakes, hot spring resorts, salt water lakes, Antarctica, water-air interface, and even from the air. They have been isolated from bottled mineral water, distilled water bottles, thermallypolluted factory discharges, cooling towers of the electric and nuclear power plants, Jacuzzi tubs, ventilation ducts, humidifiers, air-conditioning units, shower heads, kitchen sprayers, sewage, compost, vegetables, surgical instruments, contact lenses and their cases, pigeon droppings, fresh water fish, as well as other healthy, diseased, and dead animals. They have been recovered from hospitals, physiotherapeutical swimming pools, dialysis units, portable and stationary eye wash stations, human nasal cavities, throat, pharyngeal swabs, lung tissues, skin lesions, human faeces, corneal biopsies, maxillary sinus, mandibular autografts, stool samples, urine of critically ill patients, cerebrospinal fluids and the brain necropsies. Based on the above, it is accepted that Acanthamoeba is ubiquitously present in the environment and that we commonly encounter this organism in our routine lives as evidenced by the presence of antiAcanthamoeba antibodies in up to $100 \%$ healthy populations in New Zealand and more than $85 \%$ in individuals of London that came from different countries [33,34].

\section{Role in the Ecosystem}

In soil, protists such as amoebae, flagellates and ciliates have two major ecological roles: (i) influencing the structure of the microbial community, and (ii) enhancing nutrient recycling. Both of these activities are associated with soil protists feeding on bacteria thus regulating bacterial populations in the soil. Among protists, free-living amoebae are the dominant bacterial consumers and are responsible for up to $60 \%$ of the total reduction in bacterial population [35]. The primary decomposers (bacteria) directly decompose organic materials but are inefficient in releasing minerals from their own mass. The secondary decomposers, such as free-living amoebae, consume the primary decomposers and release mineral nutrients as waste products that are tied up in the primary decomposer's biomass. In this way, protists such as Acanthamoeba (as well as other grazers) make nutrients available that would otherwise remain inaccessible for much longer. The soil containing Acanthamoeba and bacteria showed significantly greater mineralization of carbon, nitrogen, and phosphorous compared with the soil containing bacteria but without Acanthamoeba [36,37]. As well as bacterial consumption, amoebae promote bacterial populations in the soil. The mineral regeneration by the secondary decomposers (protists such as amoebae), relieved nutrient limitation for the primary decomposers. This was demonstrated with the findings that when nitrogen was limiting (but carbon present), nitrogen mineralization by Acanthamoeba permitted continued growth of bacteria (Pseudomonas paucimobilis) resulting in a greater bacterial biomass [36,37]. And when carbon was limiting, Acanthamoeba was almost entirely responsible for nitrogen mineralization, with bacteria (Pseudomonas paucimobilis) contributing little. Using an experimental model system, the effects of grazing by Acanthamoeba on the composition of bacterial communities in the rhizosphere of Arabidopsis thaliana demonstrated reduction in bacterial populations leading to positive effect on plant growth [35-37]. Overall, Acanthamoeba appears to play an important role in the regulation of bacterial populations in the environment and the nutrient cycling, thus contributing to the functioning of the ecosystems.

\section{Genotyping}

Based on rRNA gene sequences, the genus Acanthamoeba is divided into 17 different genotypes to date (T1 - T17) (Table 2) [38-41]. Each genotype exhibits 5\% or more sequence divergence between different genotypes. The majority of human infections due to Acanthamoeba have been associated with the isolates of the T4 genotype. For example, more than $90 \%$ of Acanthamoeba keratitis (AK) cases have been linked with this genotype. Similarly, T4 has been the major genotype associated with the non-keratitis infections such as AGE and cutaneous infections. At present, it is unclear why T4 isolates are most abundant in human infections but it is likely due to their greater virulence and properties that enhance their transmissibility as well as their reduced susceptibility to chemotherapeutic agents. Future studies will identify virulence traits and genetic markers limited only to certain genotypes, which 
Table 2 Known Acanthamoeba genotypes and their associations with human diseases, i.e., keratitis and granulomatous encephalitis.

\begin{tabular}{ll}
\hline Acanthamoeba genotypes & Human disease association \\
\hline T1 & Encephalitis \\
\hline ^T2a & Keratitis, Encephalitis \\
\hline 土T2b - ccap1501/3c-alike sequences & NA \\
\hline T4* & Keratitis \\
\hline T5 & Keratitis, Encephalitis \\
\hline T6 & Keratitis, Encephalitis \\
\hline T7 & Keratitis \\
\hline T8 & NA \\
\hline T9 & NA \\
\hline T10 & NA \\
\hline T11 & Keratitis, Encephalitis \\
\hline T12 & Keratitis \\
\hline T13 & Encephalitis \\
\hline T14 & NA \\
\hline T15 & NA \\
\hline T16 & Keratitis \\
\hline
\end{tabular}

*this genotype has been most associated with both diseases

$\wedge$ basis of T2 division into T2a and T2b has been proposed by Maghsood et al., (2005)

NA - no disease association has been found yet

may help clarify these issues. A current list of genotypes and their association with the human infections is presented in Table 2.

\section{Acanthamoeba keratitis}

Although it can occur in non-contact lens wearers, it is mostly associated with the use of contact lenses. Overall this is a multifactorial process involving (i) contact lens wear for extended periods of time, (ii) lack of personal hygiene, (iii) inappropriate cleaning of contact lenses, (iv) biofilm formation on contact lenses, and (v) exposure to contaminated water [3]. The sequence of events in AK involves breakdown of the epithelial barrier, stromal invasion by amoebae, keratocyte depletion, induction of an intense inflammatory response, photophobia and finally stromal necrosis with blinding consequences (Figure 5) [42,43]. Recent studies have reported a significant increase in the number of AK patients in the USA, Australia, Italy, New Zealand, and Brazil [44-48]. This is further supported with 2 recent outbreaks of AK where a dramatic rise was seen in tertiary care centers in Singapore and the United States [49]. At present there are more than 120 million people wearing contact lenses, throughout the world, thus there is a growing need to be aware of the associated risks. This is particularly important in view of the ineffectiveness of cleaning solutions of some contact lens products. For example in 2006, Bausch \& Lomb (USA) voluntarily withdrew their contact lens solution "ReNu with MoistureLoc contact lens solution" from the market. This was a result of an outbreak of eye infection in the contact lens wearers http://www.drugattorneys.com/fda-reports/fusariumkeratitis-051906.cfm resulting in hundreds of lawsuits being brought against Bausch \& Lomb. The company recognized the problem and removed all $\mathrm{ReNu}$ with MoistureLoc products worldwide. This is not a one-off. Since the discovery of the first corneal lenses in 1949, there have been several outbreaks of contact lens-associated infections throughout the world with microbial ones being the most serious ones. Time and time again, the negligence of many manufacturers has been highlighted. For example in 2005, Dr. Epstein alerted Bausch \& Lomb of the

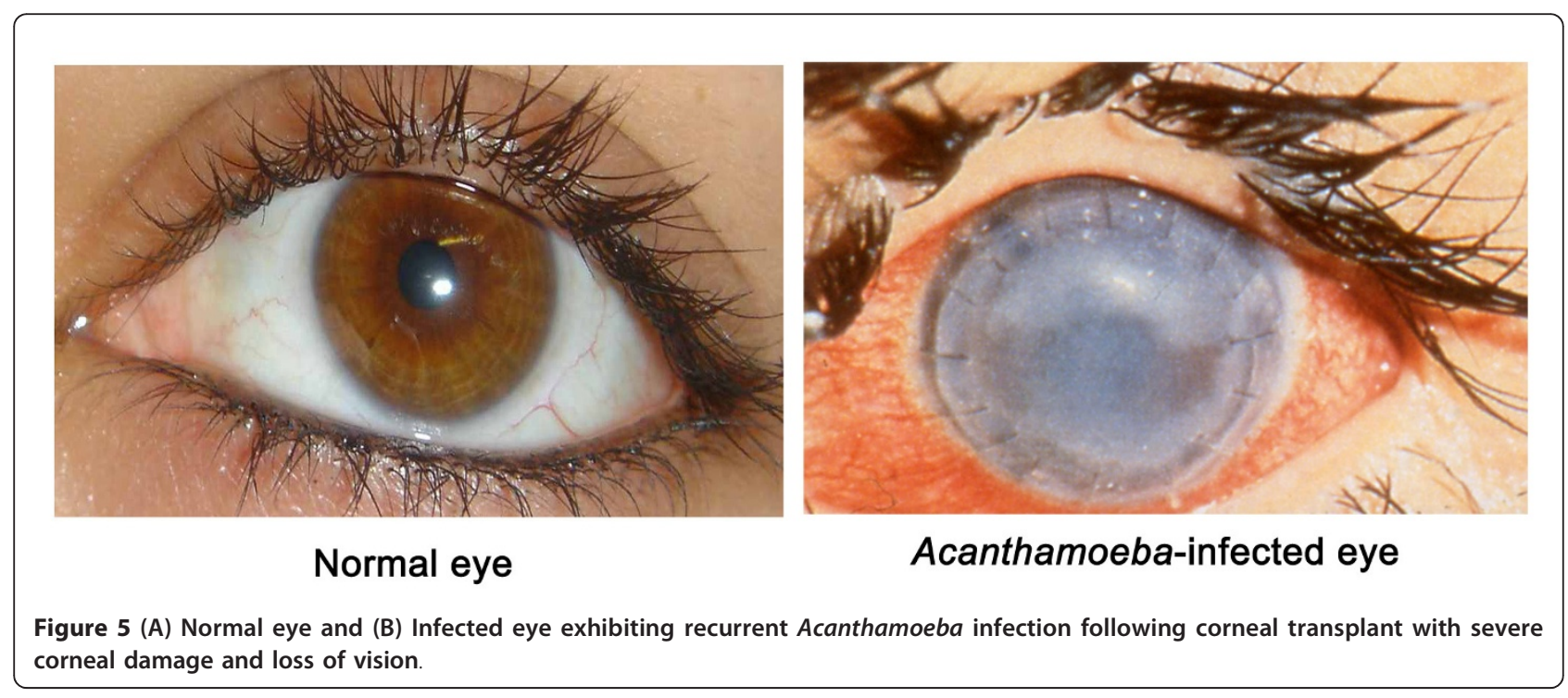


ineffectiveness of their $\mathrm{ReNu}$ with MoistureLoc contact lens solution to kill Fusarium, a claim that was rejected by the manufacturer. Again, in 2007, the Centers for Disease Control and Prevention (CDC) issued a public health alert about an increased AK risk. This outbreak was linked primarily to Complete Moisture Plus No-Rub contact lens solution. The manufacturer, Advanced Medical Optics (AMO), had voluntarily recalled the solution and was encouraging consumers not to use it until further information was available. Overall, there is a clear need to be aware of the associated risks of the contact lens use, particularly in developing countries, where health surveillance may not be appropriate.

\section{Diagnosis}

The diagnosis of AK is problematic and it is often misdiagnosed as bacterial, viral or fungal keratitis. The use of contact lenses by the patient together with excruciating pain is strongly indicative of this infection. The use of in vivo confocal microscopy has emerged as a valuable non-invasive tool for the clinical diagnosis in severe infectious keratitis with high sensitivity $[50,51]$. The confirmatory evidence comes from demonstrating parasites using laboratory-based assays. The cultivation of Acanthamoeba from the corneal biopsy or from contact lenses/cases remains the most widely used assay. Immunofluorescence assays and multiplex real-time PCR methods [52] have also been developed. The multiplex assay is of value for the simultaneous detection of pathogenic free-living amoebae in the same sample. The use of real-time fast-duplex TaqMan PCR for the simultaneous detection of 10 different genotypes of Acanthamoeba can detect $0.1 \mathrm{cyst} / \mu \mathrm{l}$ [53]. In addition, matrixassisted laser desorption-ionization time-of-flight mass spectrometry and ${ }^{1} \mathrm{H}$ NMR spectroscopy has been shown to be of potential value in the rapid identification of Acanthamoeba in the clinical specimens.

\section{Treatment}

Early diagnosis followed by aggressive treatment is essential for the successful prognosis. No single agent is shown to be uniformly effective against all isolates/genotypes of Acanthamoeba. Multiple factors including varied clinical presentation and virulence of Acanthamoeba account for a lack of correlation between in vitro activity and in vivo efficacy. The treatment regimen includes polyhexamethylene biguanide or chlorhexidine digluconate together with propamidine isethionate or hexamidine, is effective. If bacteria are also associated with the infection, addition of antibiotics, i.e., neomycin or chloramphenicol is recommended [54].

\section{Acanthamoeba granulomatous encephalitis}

AGE is a rare infection but it almost always proves fatal. It is of major concern in view of increasing numbers of immunocompromised patients who are susceptible hosts, individuals undergoing immunosuppressive therapy and excessive use of steroids. Individuals with lymphoproliferative or hematologic disorders, diabetes mellitus, pneumonitis, renal failure, liver cirrhosis or other hepatic diseases, gamma-globulinaemia or patients undergoing organ/tissue transplantation with immunosuppressive therapy, steroids and excessive antibiotics are at risk $[55,56]$. The gross pathology of the autopsied brains show severe edema and haemorrhagic necrosis. The microscopic findings of the post-mortem necropsies reveal amoebae cysts, predominantly in the perivascular spaces in the parenchyma indicating involvement of the cerebral capillaries as the sites of amoebae entry into the CNS. It is widely accepted that the route of entry for Acanthamoeba include the respiratory tract leading to amoebae invasion of the alveolar blood vessels, followed by the haematogenous spread. Acanthamoeba entry into the CNS most likely occurs through the blood-brain barrier $[55,56]$. As AGE is a secondary infection, it is difficult to determine its true burden on human health. The approximate rate of AGE-associated deaths has been suggested as 1.57 deaths per 10,000 HIV/AIDS deaths [3].

\section{Diagnosis}

The symptoms of AGE are similar to other CNS infections including virus, bacteria and fungi. The neurological manifestations of AGE may vary and include headache, fever, behavioral changes, hemiparesis, lethargy, stiff neck, agitation, aphasia, ataxia, vomiting, nausea, cranial nerve palsies, increased intracranial pressure, seizures, and coma $[55,56]$. The magnetic resonance imaging or computerized tomography of the brain shows ring-enhancing lesions exhibiting a single or multiple space-occupying mass in the cerebral cortex but severely immunocompromised patients may not exhibit such lesions. The CSF findings shows pleocytosis with lymphocytic predominance, increased protein concentrations, decreased glucose concentrations and minimal cloudiness [2], however the CSF may be devoid of cells in HIV-positive patients. High levels of Acanthamoeba-specific antibodies in patient's serum is indicative of AGE infection. The antibody levels in normal populations may be in the range of $1: 20$ to $1: 60$ [33,57] but patients with severely impaired immune system may not develop a high titre. The confirmatory evidence comes from demonstration of amoebae in the infected tissues. 


\section{Treatment}

There is no recommended treatment and the majority of cases are diagnosed at the post-mortem stage. A lack of available antiamoebic compounds together with selectivity of the blood-brain barrier has led to more than $90 \%$ mortality rate. Few successful cases involved the use of ketoconazole, fluconazole, sulfadiazine, pentamidine isethionate, amphotericin $\mathrm{B}$, azithromycin, itraconazole, or rifampicin $[1,58,59]$ but overall the prognosis remains poor.

\section{Pathogenesis}

Parasite adhesion to the host cell is a primary step and is mediated by a $130 \mathrm{kDa}$ mannose-binding protein (MBP) expressed on the surface of Acanthamoeba [60]. Acanthamoeba $\mathrm{mbp}$ consists of 6 exons and 5 introns that spans $3.6 \mathrm{kbp}$. The $2.5 \mathrm{kbp}$ cDNA codes for an 833 amino acids precursor protein with a signal sequence (residues 1-21aa), an $N$-terminal extracellular domain (residues 22-733aa) with five $N$ - and three $O$-glycosylation sites, a transmembrane domain (residues 734755aa), and a $C$-terminal intracellular domain (residues 756-833aa). Other adhesins include a laminin-binding protein with a predicted molecular mass of a $28.2 \mathrm{kDa}$, a $55 \mathrm{kDa}$ laminin-binding protein and a > $207 \mathrm{kDa}$ adhesin $[61,62]$. The initial binding leads to secondary events such as phagocytosis and toxin production resulting in the host cell death in a phosphotidylinositol 3kinasedependent (PI3K) manner [63]. The downstream effectors of PI3K involves activation of proapoptotic molecules, Bak and Bax, loss of mitochondrial membrane potential and release of cytochrome $c$ as well as caspase activation, all well-known mediators of the apoptosis [64-66]. Among host cell receptors, Toll-like receptor 4 (TLR4) showed involvement in Acanthamoeba recognition and exerting an effect through adaptor protein, Myeloid differentiation primary response 88 that led to the activation of transcription factors, nuclear factor-kappa B signalling through extracellular signalregulated kinases (ERKs) inducing the secretion of cytokines including interleukin-8, tumor necrosis factoralpha and interferon-beta in human corneal cells [67]. Using human brain microvascular endothelial cells (HBMEC), which constitute the blood-brain barrier, it is shown that Acanthamoeba abolished the HBMEC transendothelial electrical resistance by degrading occludin and zonula occludens- 1 tight junction proteins in a Rho kinase-dependent manner leading to increased permeability [68].

Other factors that may contribute to Acanthamoeba pathogenesis include ecto-ATPases of approximate molecular weights of $62,100,218,272,>300 \mathrm{kDa}$ [66] and these are involved in caspase- 3 activation (Figure 6) [69]. The neuraminidase activities of Acanthamoeba could be relevant in the colonization of the parasite, and also important in producing damage of the sialic acidrich corneal epithelium and in the alterations of glycolipids associated with meningoencephalitis. Interestingly, the neuraminidases of Trypanosoma cruzi and Acanthamoeba are immunologically related as demonstrated by antibodies against neuraminidase of Trypanosoma cruzi, which reacted with Acanthamoeba [70]. Two superoxide dismutases have been identified in Acanthamoeba: an iron superoxide dismutase $(\sim 50 \mathrm{kDa})$ and a copper-zinc superoxide dismutase $(\sim 38 \mathrm{kDa})$. The superoxide dismutase catalyzes the dismutation of the superoxide into oxygen and hydrogen peroxide and play a role in antioxidant defence. These enzymes may provide additional targets for chemotherapy and immuno-diagnosis of Acanthamoeba infections. Acanthamoeba has been shown to display plasminogen activator activity by catalyzing the cleavage of host plasminogen to form plasmin, which can activate host matrix metalloproteinases leading to degradation of the basement membranes.

Of contact-independent factors, Acanthamoeba possess hydrolytic enzymes including elastases [71], phospholipases [72], glycosidases and a variety of serine, cysteine and metalloproteases (Figure 6) [2,3,42,43]. However, their precise mechanisms of action at the molecular-level are only beginning to emerge. That some of the above proteases are secreted only by the clinical isolates may indicate their role as potent virulence factors and/or diagnostic targets. Future studies in the role of proteases as vaccine targets, search for novel inhibitors by screening of chemical libraries, or rational development of drugs based on structural studies will enhance our ability to target this pathogen. Overall, the mechanism by which Acanthamoeba breaches biological barriers is complex and is likely to involve both parasite (adhesins, proteases, phospholipases) as well as host determinants [interleukin-beta, interleukin-alpha, tumor necrosis factor- alpha, interferon-gamma, host cell apoptosis]. In addition to aforementioned potential virulence factors, the ability of Acanthamoeba to survive harsh environmental conditions and its resistance to chemotherapeutic drugs by differentiating into cysts contributes to its pathogenicity.

\section{Immune response to Acanthamoeba infections}

The recurrence of $\mathrm{AK}$ infections is common, suggesting that the corneal infection alone does not induce protective immunity against the parasite antigens. Experimental animals immunized orally with Acanthamoeba antigens mixed with the cholera toxin showed significantly lower infection rates compared with the control groups (21.4\% versus $72.6 \%$ respectively) and protection was associated with higher levels of parasite-specific sIgA. More specifically, oral immunization using 


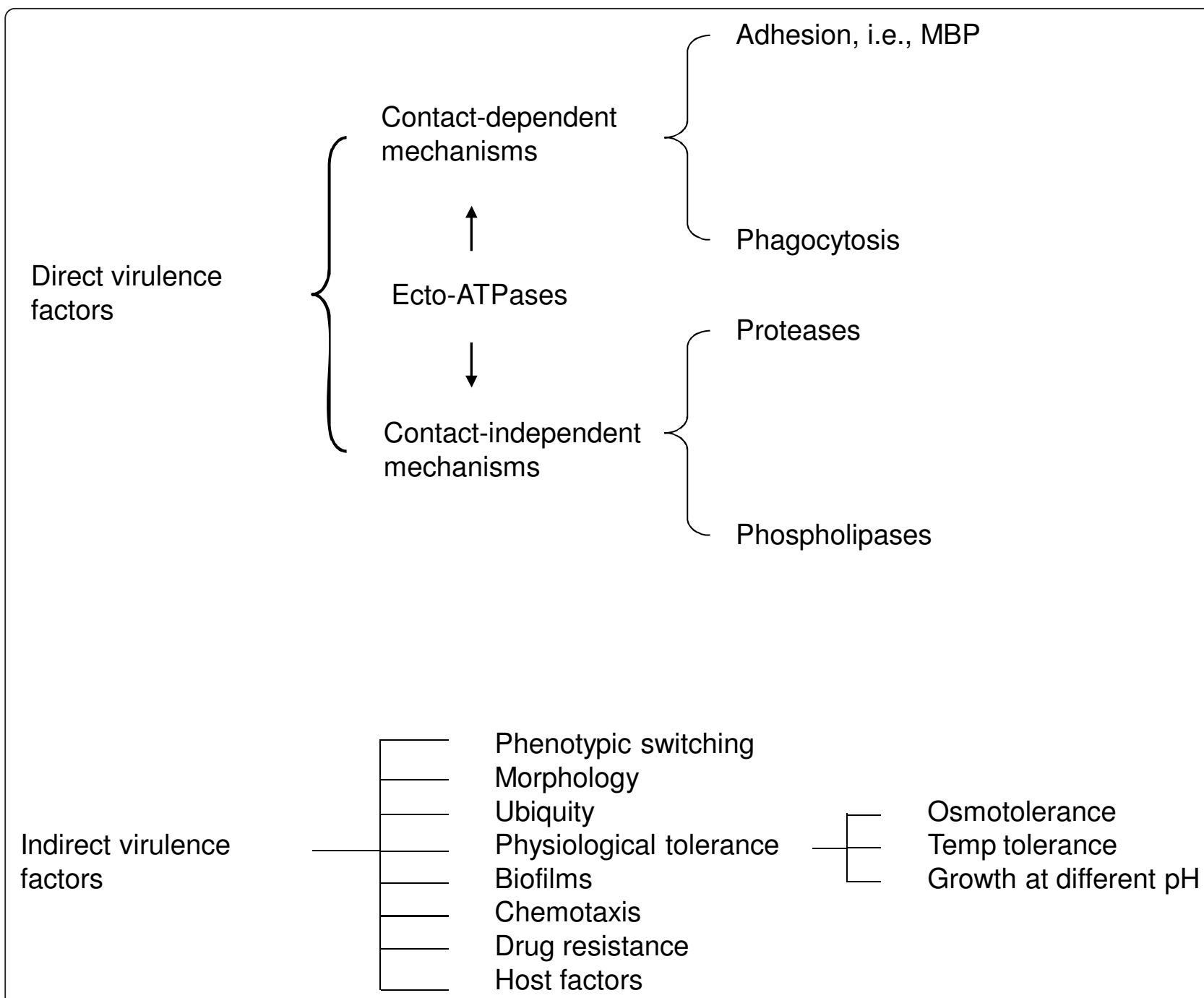

Figure 6 Acanthamoeba pathogenesis involves contact-dependent and -independent factors together with indirect virulence features (taken from Khan NA Acanthamoeba: Biology and Pathogenesis, Caister Academic Press, 2009, ISBN: 978-1-904455-43-1).

recombinant MBP improved $\mathrm{AK}$ and protection was associated with the presence of elevated levels of antiMBP sIgA in tears of the immunized animals [73]. Similarly, oral immunization with a serine protease $(\sim 133$ $\mathrm{kDa}$ ) reduced the severity of the corneal infection by modulating MMP-2 and MMP-3 expression [74]. Overall, it is suggested that AK patients show decreased overall levels of sIgA as well as specific anti-Acanthamoeba sIgA, however the role of sIgA was questioned in a recent study in which neither normal tears nor AK tears had any protective effects on Acanthamoebamediated corneal epithelial cell cytotoxicity. Tear factors, in addition to sIgA such as lysozyme, lactoferrin, beta-lysins, prostoglandins, and other compounds with antimicrobial and immunological properties were also shown to have no significant effects on Acanthamoebamediated binding to and cytotoxicity of human corneal epithelial cells [75]. Tears also contain complement that is composed of serum-borne molecules in a cascade-like manner. Acanthamoeba directly activates the complement system via the alternative pathway, however pathogenic amoebae are resistant to complement-mediated lysis due to expression of complement regulatory proteins including decay accelerating factor [76]. The presence of macrophages in corneas exposed to the parasite-laden contact lenses prevented the development of full-blown AK in vivo by inducing an inflammatory response, in particular secretion of macrophage inflammatory protein-2 [77].

For AGE, immunization with Acanthamoeba antigens using intranasal, intraperitoneal, intravenous or oral routes of administration had a protective effect validating that AGE is limited to individuals with a weakened immune response. The complement pathway and 
antibodies in the presence of phagocytes show potent lytic activity against Acanthamoeba in a contact-dependent manner. These interactions also stimulate secretion of pro-inflammatory cytokines including interleukin-1beta, interleukin-6 and tumor necrosis factor-alpha [76-79]. Other studies in mice have shown significant increased natural killer cell activities in Acanthamoebainfected animals suggesting that natural killer cells may also play a role in the protective immunity [80]. Overall, a debilitated immune status of the host is a pre-requisite in AGE but the underlying mechanisms together with the role of the host ethnic origin (i.e., genetic predisposition) remain incompletely understood. Pathogenic Acanthamoeba are shown to degrade chemokines and cytokines, antibodies, complement pathway, and macrophages $[76,81,82]$.

\section{Future prospects for treatment}

A murine monoclonal anti-idiotypic antibody and a synthetic killer mimotope (mimics a yeast killer toxin) showed broad spectrum anti-amoebic activities suggesting their potential use in the prevention and therapy of Acanthamoeba infections [83]. The Fab fragment of a monoclonal antibody specifically reactive to A. castellanii cell surface was covalently linked to the A chain of diphtheria toxin [84]. This immunotoxin inhibited cell division completely, suggesting that specific antibodies coupled with cytotoxic agents could be a useful method in the development of therapeutic interventions or preventative measures. To enhance the potency of available drugs, propamidine isethionate combined with dimethylsulfoxide proved to be highly effective suggesting that use of a carrier for known anti-amoebic drugs may increase their penetration into the cyst form of the organism, which is normally refractory to drug treatment. To this end, the use of liposomes has been shown to improve the potency of pentamidine isethionate in vitro [85]. Similarly, the use of chitosan microspheres improved in vitro anti-amoebic activity of rokitamycin. Such methods will be useful in transporting the drug for either ocular application to treat AK or nasal administration as an alternative route for the administration of the drug to the brain in AGE therapy. Small interfering RNAs (siRNAs) against the catalytic domains of extracellular serine proteases and glycogen phosphorylase showed promise in the rational development of therapeutic interventions [86]. Photodynamic chemotherapy by linking amoeba-specific antibodies with photosensitizers such as phthalocyanine or Hypocrellins B may be advantageous over conventional methods due to its localized use, in particular for eye infections. In addition, the programmed cell death in protists has emerged as a fascinating field of parasite biology and could serve as a basis of novel anti-Acanthamoebic drugs [87-89].

\section{Acanthamoeba: Trojan Horse of the Microbial World}

The majority of Acanthamoeba isolates harbor endosymbionts which may include viruses, yeast, protists and bacteria, some of which are potential human pathogens. The exact nature of symbiosis and the benefit they represent for the amoeba host are unknown. It is suggested that such interactions may help transmit microbial endosymbionts to the susceptible hosts and/or endosymbionts may contribute to the pathogenicity of Acanthamoeba $[3,90]$. Future studies in the identification of virulence factors of the endosymbiont and of the host, and their precise role in disease will clarify these issues.

Acanthamoeba is known to host the largest known virus, Mimivirus, initially mistaken for a parasitic bacterium with a particle size of $400 \mathrm{~nm}$ and genome size of 1.2 million bp [91]. Among 911 protein coding genes, $10 \%$ exhibit similarity to proteins of known functions blurring the established boundaries between viruses and Archea/Bacteria, a finding that may have huge implications in our understanding of the evolutionary processes [3,91].

Acanthamoeba is shown to harbour a variety of viruses including coxsackieviruses, adenoviruses, poliovirus, echovirus, enterovirus, or vesicular stomatitis virus, and yeast, Cryptococcus neoformans, Blastomyces dermatitidis, Sporothrix schenckii, Histoplasma capsulatum, Streptomyces californicus and Exophiala dermatitidis, and protists including Cryptosporidium and Toxoplasma gondii $[3,91]$.

Among bacterial pathogens, Acanthamoeba are shown to host/reservoir for Aeromonas spp., Bacillus cereus, Bartonella spp., Burkholderia spp., Burkholderia pickettii, Campylobacter jejuni, Candidatus Odyssella thessalonicensis, Chlamydophila pneumoniae, Coxiella burnetii, Cytophaga spp., Escherichia coli O157, neuropathogenic Escherichia coli K1, Flavobacterium spp., Francisella tularensis, Helicobacter pylori, Legionella pneumophila, Listeria monocytogenes, Staphylococcus aureus, Methicillin-resistant Staphylococcus aureus, Mycobacteria tuberculosis, M. avium, M. leprae, Parachlamydia Acanthamoebae, Pasteurella multocida, Prevotella intermedia, Porphyromonas gingivalis, Pseudomonas aeruginosa, Rickettsia, Salmonella typhimurium, Shigella dysenteriae, S. sonnei, Simkania negevensis, Vibrio cholerae, V. parahaemolyticus, Waddlia chondrophila as well as novel bacterial endosymbionts that are related to Caedibacter caryophilus, Holospora elegans and Holospora obtuse, which were proposed as 'Candidatus Caedibacter Acanthamoebae', 'Candidatus Paracaedibacter Acanthamoebae' and 'Candidatus Paracaedibacter symbiosus' suggesting the usefulness of amoeba co-culture to recover novel chlamydial strains [3,91]. With the remarkable implications of parasite-parasite interactions, 
which may contribute to the evolution of one (either bacteria or Acanthamoeba) or both parasites to become successful human and animal pathogens and transmission of microbial pathogens in the environment, this area of research is of particular significance.

\section{Conclusions}

Acanthamoeba has gained increasing attention from the scientific community studying cellular microbiology, environmental biology, physiology, cellular interactions, molecular biology, biochemistry and the evolutionary studies. This is due to their versatile roles in the ecosystem and their ability to capture prey by phagocytosis (similar to macrophages), act as vectors, reservoirs and as a Trojan horse for microbial pathogens, and to produce serious human infections including a blinding keratitis and fatal encephalitis. This unicellular organism has been used extensively to understand the molecular biology of cell motility. Being a eukaryote, Acanthamoeba presents an excellent model for cell differentiation studies. The recent availability of the Acanthamoeba genome, together with the development of transfection assays and the RNA interference methods [86] will undoubtedly increase the pace of our understanding of this complex but fascinating organism.

\section{Acknowledgements}

The authors would like to stress the fact that the work presented in this review is the results of the dedication and insights of many scientists who contributed considerably to our understanding of this fascinating organism. The work is partially supported by the Royal Society, The Nuffield Foundation, British Council for Prevention of Blindness, University of Nottingham and Aga Khan University.

\section{Author details}

${ }^{1}$ The Aga Khan University, Karachi, Pakistan. ${ }^{2}$ School of Veterinary Medicine and Science, University of Nottingham, England, UK.

\section{Authors' contributions}

NK conceived the study. RS and NK wrote the original manuscript. Al authors approved the final manuscript.

\section{Competing interests}

The authors declare that they have no competing interests.

Received: 22 July 2011 Accepted: 10 January 2012

Published: 10 January 2012

\section{References}

1. Visvesvara GS, Moura H, Schuster FL: Pathogenic and opportunistic freeliving amoebae: Acanthamoeba spp., Balamuthia mandrillaris, Naegleria fowleri, and Sappinia diploidea. FEMS Immunol Med Microbiol 2007, 50:1-26.

2. Marciano-Cabral F, Cabral G: Acanthamoeba spp. as agents of disease in humans. Clin Microbiol Rev 2003, 16:273-307.

3. Khan NA: Acanthamoeba: biology and increasing importance in human health. FEMS Microbiol Rev 2006, 30(4):564-95.

4. Taylor PW: Isolation and experimental infection of free-living amebae in freshwater fishes. J Parasitol 1997, 63:232-7.

5. Van der Lugt JJ, Van der Merwe HE: Amoebic meningoencephalitis in a sheep. J S Afr Vet Assoc 1990, 61:33-6.

6. Kinde H, Read DH, Daft BM, Manzer M, Nordhausen RW, Kelly DJ, Fuerst PA, Booton G, Visvesvara GS: Infections caused by pathogenic free-living amebas (Balamuthia mandrillaris and Acanthamoeba sp.) in horses. J Vet Diagn Invest 2007, 19:317-22.

7. Losch FD: Massenhafte entwickelung von amoben im dikdarm. J Anat Physiol 1875, 65:196-211.

8. Jackson TFHG: Entamoeba histolytica and Entamoeba dispar are distinct species; clinical, epidemiological and serological evidence. Int J Parasitol 28:181-6.

9. Schaudinn F: Untersuchungen fiber die Fortpflanzung einiger Rhizopoden (Vorlaufige Mittheilung). Arbeit Kaiserl Gesund 1903, 19:547-576.

10. Clark CG: Amoebic disease. Entamoeba dispar, an organism reborn. Royal Society of Tropical Medicine and Hygiene meeting at Manson House, London, 19 February 1998. Trans R Soc Trop Med Hyg 1998, 92:361-4.

11. Diamond LS, Clark CG: A redescription of Entamoeba histolytica Schaudinn, 1903 (Emended Walker, 1911) separating it from Entamoeba dispar Brumpt, 1925. J Euk Microbiol 1993, 40:340-4.

12. Costa CA, De Brito KN, Gomes MA, Caliari MV: Histopathological and immunohistochemical study of the hepatic lesions experimentally induced by Entamoeba dispar. Eur J Histochem 2010, 54(3):e39.

13. Ximénez $C$, Cerritos R, Rojas L, Dolabella $S$, Morán P, Shibayama M, González E, Valadez A, Hernández E, Valenzuela O, Limón A, Partida O Silva EF: Human amebiasis: breaking the paradigm? Int J Environ Res Pub Health 2010, 7(3):1105-20.

14. De Jonckheere JF: A century of research on the Amoeboflagellate Genus Naegleria. Acta Protozool 2002, 41:309-42.

15. Gelman BB, Rauf SJ, Nader R, Popov V, Borkowski J, Chaljub G, Nauta HW, Visvesvara GS: Amoebic encephalitis due to Sappinia diploidea. J Am Med Assoc 2001, 285:2450-1.

16. Visvesvara GS, Schuster FL, Martinez AJ: Balamuthia mandrillaris, N. G., N. Sp., agent of amebic meningoencephalitis in humans and other animals. J Euk Microbiol 1993, 40:504-14.

17. Castellani A: An amoeba found in culture of yeast: preliminary note. $J$ Trop Med Hyg 1930, 160.

18. Bowers B, Korn ED: Cytochemical identification of phosphatase activity in the contractile vacuole of Acanthamoeba castellanii. J Cell Biol 1973, 59:784-91

19. Dearborn DG, Korn ED: Lipophophonoglycan of the plasma membrane of Acanthamoeba castellanii, fatty acid composition. J Biol Chem 1974, 249:3342-6.

20. Smith FR, Korn ED: 7-Dehydrostigmasterol and ergosterol: the major sterol of an amoebae. J Lipid Res 1968, 9:405-8.

21. Ulsamer AG, Wright PL, Wetzel MG, Korn ED: Plasma and phagosome membranes of Acanthamoeba castellanii. J Cell Biol 1971, 51:193-215.

22. Hadas $\mathrm{E}$, Mazur T: Biosynthesis of prostaglandins in pathogenic and nonpathogenic strains of Acanthamoeba spp. Parasitol Res 1997, 83:296-9.

23. Burger G, Plante I, Lonergan KM, Gray MW: The mitochondrial DNA of the amoeboid protozoon, Acanthamoeba castellanii: complete sequence, gene content and genome organization. J Mol Biol 1995, 245:522-37.

24. Anderson IJ, Watkins RF, Samuelson J, Spencer DF, Majoros WH, Gray MW Loftus BJ: Gene discovery in the Acanthamoeba castellanii genome. Protist 2005, 156:203-14.

25. Pollard TD, Shelton E, Weihing RR, Korn ED: Ultrastructural characterization of F-actin isolated from Acanthamoeba castellanii and identification of cytoplasmic filaments as F-actin by reaction with rabbit heavy meromyosin. J Mol Biol 1970, 50:91-7.

26. Preston TM, Richard H, Wotton RS: Locomotion and feeding of Acanthamoeba at the water-air interface of ponds. FEMS Microbiol lett 2001, 194:143-7

27. Band RN, Mohrlok S: The cell cycle and induced amitosis in Acanthamoeba. J Protozool 1973, 20:654-7.

28. Weisman RA: Differentiation in Acanthamoeba castellanii. Ann Rev Microbiol 1976, 30:189-219.

29. Tomlinson $G$, Jones EA: Isolation of cellulose from the cyst wall of a soil amoeba. Biochim Biophys Acta 1962, 63:194-200.

30. Hirukawa Y, Nakato H, Izumi S, Tsuruhara T, Tomino S: Structure and expression of a cyst specific protein of Acanthamoeba castellanii. Biochim Biophys Acta 1998, 1398:47-56.

31. Neff RJ, Neff RH: The biochemistry of amoebic encystment. Symp Soc Exp Biol 1969, 23:51-81. 
32. Dudley R, Jarroll EL, Khan NA: Carbohydrate analysis of Acanthamoeba castellanii. Exp Parasitol 2009, 122:338-43.

33. Cursons RT, Brown TJ, Keys EA, Moriarty KM, Till D: Immunity to pathogenic free-living amoebae: role of humoral antibody. Infect Immun 1980, 29:401-7.

34. Brindley N, Matin A, Khan NA: Acanthamoeba castellanii: high antibody prevalence in racially and ethnically diverse populations. Expe Parasitol 2009, 121:254-6.

35. Sinclair JL, McClellan JF, Coleman DC: Nitrogen Mineralization by Acanthamoeba polyphaga in Grazed Pseudomonas paucimobilis Populations. Appl Environ Microbiol 1981, 42:667-71.

36. Rønn R, McCaig AE, Griffiths BS, Prosser Jl: Impact of protozoan grazing on bacterial community structure in soil microcosms. Appl Environ Microbiol 2002, 68:6094-105.

37. Rosenberg K, Bertaux J, Krome K, Hartmann A, Scheu S, Bonkowski M: Soil amoebae rapidly change bacterial community composition in the rhizosphere of Arabidopsis thaliana. Int Soc Microb Ecol J 2009, 3:675-84.

38. Stothard DR, Schroeder-Diedrich JM, Awwad MH, Gast RJ, Ledee DR, Rodriguez-Zaragoza S, Dean CL, Fuerst PA, Byers TJ: The evolutionary history of the genus Acanthamoeba and the identification of eight new 18S rRNA gene sequence types. J Euk Microb 1998, 45:45-54.

39. Booton GC, Visvesvara GS, Byers TJ, Kelly DJ, Fuerst PA: Identification and distribution of Acanthamoeba species genotypes associated with nonkeratitis infections. J Clin Microb 2005, 43:1689-93.

40. Corsaro D, Venditti D: Phylogenetic evidence for a new genotype of Acanthamoeba (Amoebozoa, Acanthamoebida). Parasitol Res 2010 107:233-8.

41. Nuprasert W, Putaporntip C, Pariyakanok L, Jongwutiwes S: Identification of a novel t17 genotype of Acanthamoeba from environmental isolates and t10 genotype causing keratitis in Thailand. J Clin Microb 2010, 48:4636-440

42. Niederkorn JY, Alizadeh H, Leher H, McCulley JP: The pathogenesis of Acanthamoeba keratitis. Microb Infect 1999, 1:437-43.

43. Panjwani N: Pathogenesis of Acanthamoeba keratitis. Ocul Surf 2010, 8:70-9

44. Thebpatiphat N, Hammersmith KM, Rocha FN, Rapuano CJ, Ayres BD, Laibson PR, Eagle RC Jr, Cohen EJ: Acanthamoeba keratitis: a parasite on the rise. Cornea 2007, 26:701-6.

45. Carvalho FR, Foronda AS, Mannis MJ, Höfling-Lima AL, Belfort R Jr, de Freitas D: Twenty years of Acanthamoeba keratitis. Cornea 2009, 28:516-9.

46. Ku JY, Chan FM, Beckingsale P: Acanthamoeba keratitis cluster: an increase in Acanthamoeba keratitis in Australia. Clin Exp Ophthalmol 2009, 37:181-90

47. Gatti S, Rama P, Matuska S, Berrilli F, Cavallero A, Carletti S, Bruno A, Maserati R, Di Cave D: Isolation and genotyping of Acanthamoeba strains from corneal infections in Italy. J Med Microbiol 2010, 59:1324-30

48. Patel DV, Rayner S, McGhee CN: Resurgence of Acanthamoeba keratitis in Auckland, New Zealand: a 7-year review of presentation and outcomes. Clin Exp Ophthalmol 2010, 38:15-20.

49. Tu EY, Joslin CE: Recent outbreaks of atypical contact lens-related keratitis: what have we learned? Am J Ophthalmol 2010, 150:602-8.

50. Vaddavalli PK, Garg P, Sharma S, Sangwan VS, Rao GN, Thomas R: Role of confocal microscopy in the diagnosis of fungal and Acanthamoeba keratitis. Ophthalmol 2011, 118:29-35.

51. Winchester K, Mathers WD, Sutphin JE, Daley TE: Diagnosis of Acanthamoeba keratitis in vivo with confocal microscopy. Cornea 1995, 14:10-7.

52. Qvarnstrom $Y$, Visvesvara GS, Sriram $R$, da Silva AJ: Multiplex real-time PCR assay for simultaneous detection of Acanthamoeba spp., Balamuthia mandrillaris, and Naegleria fowleri. J Clin Microbiol 2006, 44:3589-95.

53. Goldschmidt P, Degorge S, Benallaoua D, Saint-Jean C, Batellier L, Alouch C, Laroche $L$, Chaumeil C: New tool for the simultaneous detection of 10 different genotypes of Acanthamoeba available from the American Type Culture Collection. Br J Ophthalmol 2009, 93:1096-100.

54. Perez-Santonja JJ, Kilvington S, Hughes R, Tufail A, Metheson M, Dart JKG: Persistently culture positive Acanthamoeba keratitis; in vivoresistance and in vitro sensitivity. Ophthalmol 2003, 110:1593-600.

55. Martinez AJ: Infections of the central nervous system due to Acanthamoeba. Rev Infect Dis 1991, 13:S399-402.

56. Martinez AJ, Visvesvara GS: Free-living, amphizoic and opportunistic amebas. Brain Pathol 1997, 7:583-98.
57. Cerva L: Acanthamoeba culbertoni and Naegleria fowleri: occurrence of antibodies in man. J Hyg Epidemiol Microbiol Immunol 1989, 33:99-103.

58. Lalitha MK, Anandi V, Srivastava A, Thomas K, Cherian AM, Chandi SM: Isolation of Acanthamoeba culbertsoni from a patient with meningitis. $J$ Clin Microbiol 1985, 21:666-7.

59. Ofori-Kwakye SK, Sidebottom DG, Herbert J, Fischer EG, Visvesvara GS: Granulomatous brain tumor caused by Acanthamoeba. J Neurosurg 1986, 64:505-9.

60. Garate M, Cao Z, Bateman E, Panjwani N: Cloning and characterization of a novel mannose-binding protein of Acanthamoeba. J Biol Chem 2004 279:29849-56.

61. Hong YC, Lee WM, Kong HH, Jeong HJ, Chung DI: Molecular cloning and characterization of a CDNA encoding a laminin-binding protein (AhLBP) from Acanthamoeba healyi. Exp Parasitol 2004, 106:95-102.

62. Rocha-Azevedo BD, Jamerson M, Cabral GA, Marciano-Cabral F: Acanthamoeba culbertsoni: Analysis of amoebic adhesion and invasion on extracellular matrix components collagen I and laminin-1. Exp Parasitol 2009, 126:79-84

63. Sissons J, Kim KS, Stins M, Jayasekera S, Alsam S, Khan NA: Acanthamoeba castellanii induces host cell death via a phosphatidylinositol 3-kinasedependent mechanism. Infect Immun 2005, 73:2704-8.

64. Alizadeh H, Pidherney MS, McCulley JP, Niederkorn JY: Apoptosis as a mechanism of cytolysis of tumor cells by a pathogenic free-living amoeba. Infect Immun 1994, 62:1298-303.

65. Mattana A, Cappai V, Alberti L, Serra C, Fiori PL, Cappuccinelli P: ADP and other metabolites released from Acanthamoeba castellanii lead to human monocytic cell death through apoptosis and stimulate the secretion of proinflammatory cytokines. Infect Immun 2002, 70:4424-32.

66. Chusattayanond AD, Boonsilp S, Kasisit J, Boonmee A, Warit S: Thai Acanthamoeba isolate (T4) induced apoptotic death in neuroblastoma cells via the Bax-mediated pathway. Parasitol Int 2010, 59:512-6.

67. Ren MY, WU XY: Toll-like receptor 4 signalling pathway activation in a rat model of Acanthamoeba Keratitis. Parasite Immunol 2011, 33:25-33.

68. Khan NA, Siddiqui R: Acanthamoeba affects the integrity of human brain microvascular endothelial cells and degrades the tight junction proteins. Int J Parasitol 2009, 39:1611-6.

69. Sissons J, Alsam S, Jayasekera S, Khan NA: Ecto-ATPases of clinical and non-clinical isolates of Acanthamoeba. Microb Pathog 2004 37:231-9.

70. Pellegrin JL, Ortega-Barria E, Prioli RP, Meijia JS, Pereira ME: The neuraminidases of Trypanosoma cruzi and Acanthamoeba castellanii are immunologically related. Trop Med Parasitol 1992, 43:33-7.

71. Ferrante A, Bates EJ: Elastase in the pathogenic free-living amoebae, Naegleria and Acanthamoeba spp. Infect Immun 1988, 56:3320-1.

72. Mortazavi PN, Keisary E, Loh LN, Jung SY, Khan NA: Possible roles of phospholipase A2 in the biological activities of Acanthamoeba castellanii (T4 genotype). Protist 2011, 162:168-76

73. Garate M, Alizadeh H, Neelam S, Niederkorn JY, Panjwani N: Oral immunization with Acanthamoeba castellanii mannose-binding protein ameliorates amoebic keratitis. Infect Immun 2006, 74:7032-4

74. Alizadeh $\mathrm{H}$, Li H, Neelam S, Niederkorn JY: Modulation of corneal and stromal matrix metalloproteinase by the mannose-induced Acanthamoeba cytolytic protein. Exp Eye Res 2008, 87:286-91.

75. Alsam S, Jeong SR, Dudley R, Khan NA: Role of human tear fluid in Acanthamoeba interactions with the human corneal epithelial cells. Int $J$ Med Microbiol 2008, 298:329-36.

76. Toney DM, Marciano-Cabral F: Resistance of Acanthamoeba species to complement lysis. J Parasitol 1998, 84:338-44.

77. van Klink F, Alizadeh $\mathrm{H}, \mathrm{He} \mathrm{Y}$, Mellon JA, Silvany RE, McCulley JP, Niederkorn JY: The role of contact lenses, trauma, and Langerhans cells in a Chinese hamster model of Acanthamoeba keratitis. Invest Ophthalmol Vis Sci 1993, 34:1937-44.

78. Benedetto N, Rossano F, Gorga F, Folgore A, Rao M, Romano Carratelli C: Defense mechanisms of IFN-gamma and LPS-primed murine microglia against Acanthamoeba castellanii infection. Int Immunopharmacol 2003, 3:825-34.

79. Stewart GL, Shupe KK, Kim I, Silvany RE, Alizadeh H, McCulley JP, Niederkorn JY: Antibody-dependent neutrophil-mediated killing of Acanthamoeba castellanii. Int J Parasitol 1994, 24:739-42.

80. Kim KH, Shin $\mathrm{CO}$, Im K: Natural killer cell activity in mice infected with free-living amoeba with reference to their pathogenicity. Korean J Parasitol 1993, 31:239-48 
81. Na BK, Cho JH, Song CY, Kim TS: Degradation of immunoglobulins, protease inhibitors and interleukin-1 by a secretory proteinase of Acanthamoeba castellanii. Korean J Parasitol 2002, 40:93-99.

82. Walochnik J, Obwaller A, Haller-Schober EM, Aspock H: Anti-Acanthamoeba $\lg G$, $\lg M$, and $\lg A$ immunoreactivities in correlation to strain pathogenicity. Parasitol Res 2001, 87:651-8.

83. Fiori PL, Mattana A, Dessi D, Conti S, Magliani W, Polonelli L: In vitro acanthamoebicidal activity of a killer monoclonal antibody and a synthetic peptide. J Antimicrob Chem 2006, 57:891-8.

84. Villemez CL, Carlo PL: Preparation of an immunotoxin for Acanthamoeba castellanii. Biochem Biophys Res Commun 1984, 125:25-9.

85. Siddiqui R, Syed A, Tomas S, Prieto-Garcia J, Khan NA: Effect of free versus liposomal-complexed pentamidine isethionate on biological characteristics of Acanthamoeba castellanii in vitro. J Med Microbiol 2009, 58:327-30.

86. Lorenzo-Morales J, Martín-Navarro CM, López-Arencibia A, SantanaMorales MA, Afonso-Lehmann RN, Maciver SK, Valladares B, MartínezCarretero E: Therapeutic potential of a combination of two gene-specific small interfering RNAs against clinical strains of Acanthamoeba. Antimicrob Agents Chemother 2010, 54:5151-5.

87. Lüder CG, Campos-Salinas J, Gonzalez-Rey E, van Zandbergen G: Impact of protozoan cell death on parasite-host interactions and pathogenesis. Parasit Vectors 2010, 3:116.

88. Kaczanowski S, Sajid M, Reece SE: Evolution of apoptosis-like programmed cell death in unicellular protozoan parasites. Parasit Vectors 2011, 4:44.

89. Jiménez-Ruiz A, Alzate JF, Macleod ET, Lüder CG, Fasel N, Hurd H: Apoptotic markers in protozoan parasites. Parasit Vectors 2010, 3:104.

90. Greub G, Raoult D: Microorganisms resistant to free-living amoebae. Clin Microbiol Rev 2004, 17:413-33.

91. Moreira D, Brochier-Armanet C: Giant viruses, giant chimeras: the multiple evolutionary histories of Mimivirus genes. BMC Evol Biol 2008, 8:12.

doi:10.1186/1756-3305-5-6

Cite this article as: Siddiqui and Khan: Biology and pathogenesis of Acanthamoeba. Parasites \& Vectors 2012 5:6.

\section{Submit your next manuscript to BioMed Central and take full advantage of:}

- Convenient online submission

- Thorough peer review

- No space constraints or color figure charges

- Immediate publication on acceptance

- Inclusion in PubMed, CAS, Scopus and Google Scholar

- Research which is freely available for redistribution

Submit your manuscript at www.biomedcentral.com/submit
Ciomed Central 